\title{
Acta Neurologica Belgica: a youthful centenarian
}

\author{
Michel Van Zandijcke ${ }^{1}$ (B)
}

Received: 10 July 2016/Accepted: 26 July 2016/Published online: 4 August 2016

(C) Belgian Neurological Society 2016

As the Editor-in-Chief of Acta Neurologica Belgica, I am very proud to announce that the journal Impact Factor increased from 0.894 in 2014 to 1.495 in 2015. This result would not have been possible without the efforts of my predecessor, Jean Schoenen, and the continuous help of all my six co-editors. I also have to thank the editorial staff at Springer Nature, and especially Barbara Pedrotti, senior editor, for her continuous support.

In the year 2015,827 manuscripts were submitted to Acta Neurologica Belgica. The top five countries of origin were Turkey, China, Iran, Belgium, and India. So, Asia is very well represented. The acceptance rate was quite low: $31 \%$. Despite of this, due to the increasing submissions trend, in the future, we may be obliged to be more selective and publish only high-quality papers. I hope this will stimulate authors to submit interesting manuscripts on original and actual topics. Review articles on neuroscience topics, bringing new insights to the general neurologist, are also welcome.
The readers of our journal have noticed that since 2016 Acta Neurologica Belgica has been published only in an electronic format. In my opinion, this is a natural evolution, as journals are now mainly read on laptops, tablets and smartphones. Moreover, the electronic format is a very practical tool which allows interesting articles to be saved in a searchable way. Not the least, saving printed papers it is a way to contribute to the scientific knowledge in a sustainable way.

Based on its glorious historical past with more than 100 years of scientific publications, open to the needs of the present time, I am convinced that Acta Neurologica Belgica will tend to a bright future!

Michel Van Zandijcke,

Editor-in-Chief

University Hospital, Ghent, Belgium

Michel Van Zandijcke

michel.van.zandycke@telenet.be

1 University Hospital, Ghent, Belgium 